\title{
Characteristic behaviors of CFRP and GFRP at cryogenic temperature under static and cyclic loadings
}

\author{
S. Kubo, K. Okubo \& T. Fujii \\ Department of Engineering, Doshisha University, Japan
}

\begin{abstract}
Characteristic behaviors of plain-woven Carbon Fiber Reinforced Plastics (CFRP) at cryogenic temperature were investigated under static and cyclic loading. The test results were compared with those of Glass Fiber Reinforced Plastics (GFRP). Tensile behaviors of monofilaments were also evaluated. The test results showed that two knee-points appeared in the stress-strain curve of GFRP under static load, while that of CFRP was almost linear. Both strength and failure strain of the CFRP at cryogenic temperature were lower than those of CFRP at room temperature, because the epoxy resin was brittle at cryogenic temperature. At cryogenic temperature, the knee-point was also shown in the S$\mathrm{N}$ curve of GFRP of the fatigue test but that was not shown in the S-N curve of CFRP. The elastic modulus of CFRP at cryogenic temperature suddenly decreased in the final stage of fatigue, while such change was not observed at room temperature. The thermal fatigue test where no cyclic loads were applied to the specimen was also conducted in order to investigate the damage progression due to temperature change. After the thermal fatigue test, the residual strength of the CFRP and GFRP were measured at room temperature. The change in residual strength was explained by the difference of the coefficient of thermal expansion. This paper also mentioned that, at cryogenic temperature, the stiffness reduction under cyclic loading was related to the local thermal stress by thermal cyclic fatigue. It should be said that the carbon fiber was failed with accompanying critical crack propagation of the matrix due to the brittle of resin at cryogenic temperature.
\end{abstract}

Keywords: fiber reinforced plastics, cryogenic temperature, coefficient of thermal expansion, residual strength, stiffness reduction. 


\section{Introduction}

Fiber reinforced plastics (FRP) are widely used for the structural component due to their low coefficient of thermal expansion as well as high specific strength and stiffness [1-3]. The FRPs are also expected in use at harsh environment, for example outer space and liquid fuel tank for disposable rocket. The GFRP (Glass Fiber Reinforced Plastics) has been partly used at low temperature of a ship, and Sakurai [4] discussed the strength of GFRP for them. However their use is limited but aluminium alloy is still used for many applications. To apply the FRP, for example, for the fuel tank instead of the aluminium alloy, behaviors of FRP such as CFRP (Carbon Fiber Reinforced Plastics) and GFRP under the cryogenic temperature should be cleared.

The purpose of this study is to investigate the mechanical properties of CFRP at room and cryogenic temperature using liquid nitrogen, in comparison with those of GFRP. The mechanical properties of carbon and glass monofilaments at room and cryogenic temperature were also shown. The coefficients of thermal expansions were measured for FRP as well as the epoxy resin for polymer matrix. The tensile tests of CFRP and GFRP were conducted at room and cryogenic temperature. The tension-tension cyclic loading was applied to the CFRP and GFRP with hydraulic servo testing machine having nitrogen cryostat. Thermal fatigue tests (without loading) were also conducted in which environmental temperature was alternated between room and cryogenic temperature. The residual strengths of the damaged specimens were measured at room temperature after the thermal fatigue test.
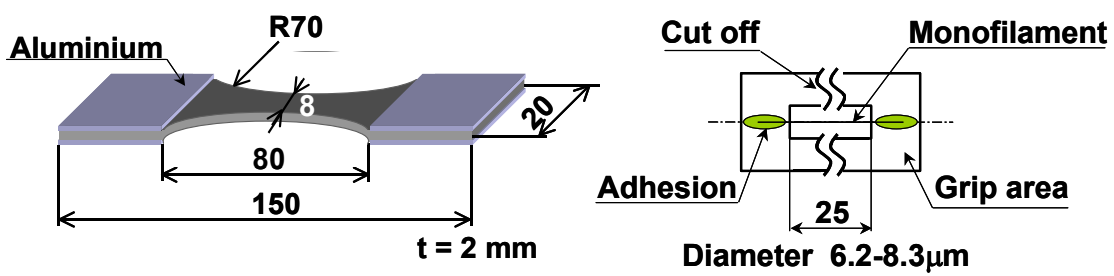

Figure 1: Dimensions of specimens of composite and monofilament.

\section{Experimental procedure}

\subsection{Materials and specimens}

Plain-woven carbon (PYROFIL TR3110M: Mitsubishi Rayon Co., Ltd.), epoxy resin (bisphenol A type) (E-828: Japan Epoxy Resins Co., Ltd.) and Cyclopolyamide (E-113: Japan Epoxy Resins Co., Ltd.) were used as reinforcement, matrix and hardener for CFRP $\left(V_{\mathrm{cf}}=65.3 \%\right)$. Glass cloth (MS253C: Asahi Fiber-Glass Co., Ltd.), polyester resin (5595APT-S: DH Material Inc.), methyl ethyl ketone per oxide (nacalai tesque) and cobalt 
naphthenate $(6 \%$ solution) (Nacalai Tesque Co., Ltd.) were used as reinforcement, matrix, hardene and catalyzer for GFRP ( $\left.V_{\mathrm{gf}}=35.0 \%\right)$, respectively. The specimen was fabricated by hand lay-up method. The dimensions of the dog-bone shaped specimens of the composites were $150 \mathrm{~mm}$ long, $20 \mathrm{~mm}$ wide and $2 \mathrm{~mm}$ thick as shown in Fig. 1. Aluminium tabs with 35 $\mathrm{mm}$ long, $20 \mathrm{~mm}$ wide and $2 \mathrm{~mm}$ thick were glued on the end of specimens. The dimensions of the specimens of carbon and glass monofilaments are also shown in Fig. 1.

\subsection{Experiments}

\subsubsection{Static tensile tests}

The carbon and glass monofilaments were extracted from their fabrics. In the tensile tests for monofilaments, at first, the diameter of monofilaments was measured using optical microscope. The tensile testing machine for monofilaments was shown in Fig. 2(a). Tensile load was applied to the monofilament at room and liquid nitrogen temperature. The test conditions of monofilaments specimens were referred to Japanese Industrial Standards (JIS R7606). The strain was calculated from the crosshead displacement.

The tensile testing machine for the composites and resin were also shown in Fig. 2(b). Extensometer was attached to the specimen to measure the strain.

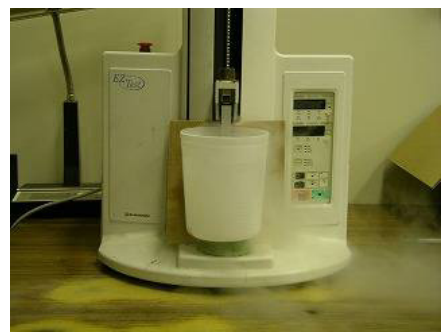

(a)

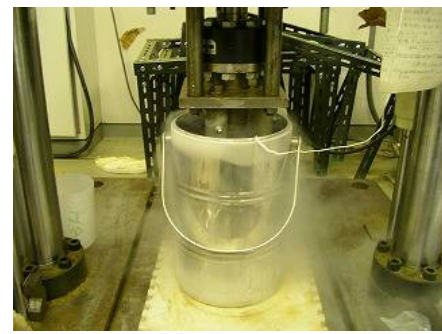

(b)

Figure 2: Tensile tests at cryogenic temperature. (a): for monofilament, (b): for composite.

\subsubsection{Thermal mechanical analysis (TMA)}

The coefficient of thermal expansion $\alpha_{m}$ of the pure epoxy resin, $\alpha_{c}$ of the CFRP were measured from $-60^{\circ} \mathrm{C}$ up to room temperature (RT) by the thermal mechanical analysis (SHIMADZU TMA-60) referred to JIS (K7197) [5]. The heating rate was $5^{\circ} \mathrm{C} / \mathrm{min}$.

\subsubsection{Tension-tension fatigue tests}

At room and cryogenic temperature, the tension-tension fatigue test was conducted with a Shimadzu Co. EHF-UB50kN at constant amplitude of load with sinusoidal wave at a frequency of $5 \mathrm{~Hz}$ and stress ratio $\mathrm{R}\left(\mathrm{R}=\sigma_{\min } / \sigma_{\max }\right)=0.1$ for CFRP and $\mathrm{R}=0$ for GFRP. 


\subsubsection{Thermal fatigue tests}

The conditions are shown in Table 1. The temperature of the specimens was alternated from cryogenic temperature to room temperature. The specimens were alternatively transferred with an aluminum frame into $\mathrm{LN}_{2}$ from ambient air. At first, specimens were cooled down to $-196{ }^{\circ} \mathrm{C}$ and kept for $2 \mathrm{~min}$. Then they were held in ambient air for $5 \mathrm{~min}$. To reduce the time required for specimens to return to the ambient temperature, a fan was used during the periods when the specimens were held in ambient temperature [6].

The residual stress was measured after thermal fatigue test.

Table 1: $\quad$ Thermal fatigue test condition.

\begin{tabular}{c|c|c|c}
\hline Materials & $T_{\max }\left({ }^{\circ} \mathrm{C}\right)$ & $T_{\min }\left({ }^{\circ} \mathrm{C}\right)$ & Maximum number of cycles \\
\hline \hline CFRP and GFRP & $23\left({ }^{\circ} \mathrm{C}\right)$ & $-196\left({ }^{\circ} \mathrm{C}\right)$ & $1,3,5,10,20,30,40,50,60,70,80,90,100$ \\
\hline
\end{tabular}

\section{Results and discussions}

\subsection{Strength and failure strain of monofilaments}

The mechanical properties of glass and carbon monofilament at room and cryogenic temperature are shown in Table 2 . The strength and the failure strain of glass monofilament were increased about $99 \%$ and $82 \%$ respectively at cryogenic temperature, compared with those at room temperature. The strength of carbon monofilament was also increased about $11 \%$, while the failure strain of carbon monofilament was decreased about $10 \%$ at cryogenic temperature. Fig. 3 and 4 show the fracture surfaces of the glass and carbon monofilament at room and cryogenic temperature, respectively. At room temperature, the typical cleavage fracture surfaces were observed in the surfaces of glass and carbon monofilament. On the other hand, at cryogenic temperature, there was rough area in the center of the fracture surface of glass and carbon monofilament.

Table 2: $\quad$ Mechanical properties of carbon and glass monofilaments.

\begin{tabular}{c|c|c|c|c|c}
\hline Materials & $\begin{array}{c}\text { Diameter } \\
{[\mu \mathrm{m}]}\end{array}$ & $\begin{array}{c}\text { Temperature } \\
{\left[{ }^{\circ} \mathrm{C}\right]}\end{array}$ & $\begin{array}{c}\text { Elastic modulus } \\
{[\mathrm{GPa}]}\end{array}$ & $\begin{array}{c}\text { Tensile strength } \\
{[\mathrm{MPa}]}\end{array}$ & $\begin{array}{c}\text { Failure str } \\
{[\%]}\end{array}$ \\
\hline \hline \multirow{2}{*}{ CF } & $6.0 \sim 8.5$ & $23 \pm 2$ (Room Temp.) & 240 & 3503 & 1.34 \\
\cline { 3 - 6 } & & -196 (Cryogenic Temp.) & 269 & 3168 & 1.22 \\
\hline \multirow{2}{*}{ GF } & $7.8 \sim 14.1$ & $23 \pm 2$ (Room Temp.) & 68.5 & 1330 & 1.70 \\
\cline { 3 - 6 } & & -196 (Cryogenic Temp.) & 67.7 & 2650 & 3.10 \\
\hline
\end{tabular}

The reduction in failure strain and strength of carbon monofilament is considered as the brittle behaviors of the carbon fiber at cryogenic 
temperature [7]. However the glass monofilament had rather different characteristics from those of carbon monofilament, in which the failure strain of the glass monofilament was increased at cryogenic temperature even though it has rough fracture surface.

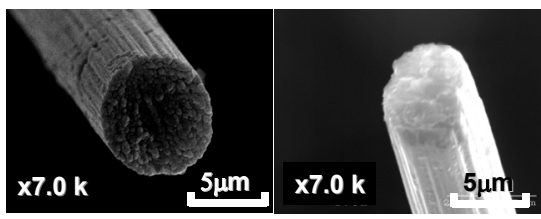

Figure 3: Fracture surface of carbon monofilament (left: at CT, right: at RT).

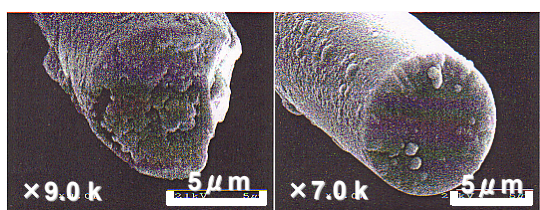

Figure 4: Fracture surface of glass monofilament (left: at CT, right: at RT).

\subsection{Static mechanical properties of CFRP and GFRP}

Static strengths were listed in Table. 3. The stress strain (S-S) curves of CFRP and GFRP at room and cryogenic temperature were shown in Fig. 5 and 6, respectively. The S-S curves of CFRP were linear at both of room and cryogenic temperature. The S-S curve of GFRP at room temperature was also linear. However, that of GFRP at cryogenic temperature showed two knee-points. The elastic modulus of the resin is usually increased while its failure strain is decreased at cryogenic temperature. Actually, the elastic modulus of CFRP and GFRP at cryogenic temperature increased in comparison with that at room temperature in this test. At cryogenic temperature, the strength and failure strain of GFRP should be contributed by the increase of the strength and failure strain of glass monofilament at cryogenic temperature. Little changes of the mechanical properties of CFRP were found in the tensile test at room and cryogenic temperature.

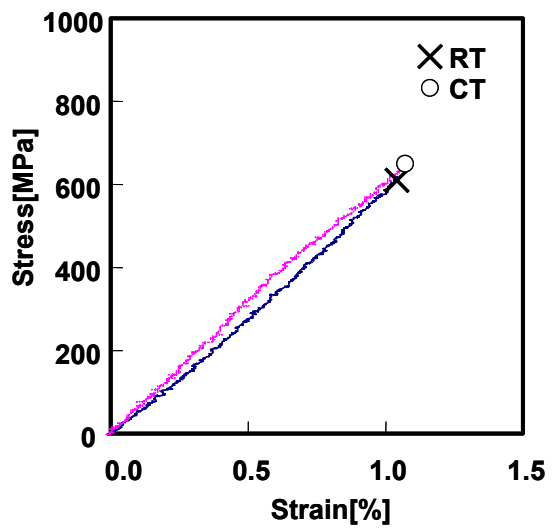

Figure 5: S-S curves of CFRP at RT and CT.

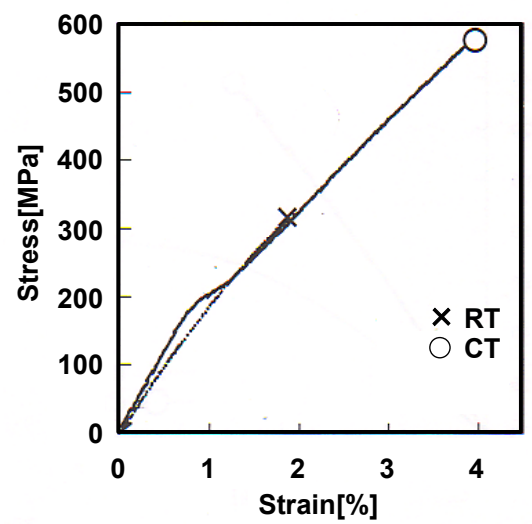

Figure 6: S-S curves of GFRP at RT and CT. 
Table 3: $\quad$ Static strength of CFRP and GFRP at RT and CT.

\begin{tabular}{c|c|c|c|c}
\hline \multirow{3}{*}{$\begin{array}{c}\text { Stress level } \\
\gamma=\sigma_{\text {max }} / \sigma_{\text {st }}[\%]\end{array}$} & \multicolumn{3}{|c}{ Static strength : $\sigma_{\text {st }}[\mathrm{MPa}]$} \\
\cline { 2 - 5 } & \multicolumn{2}{|c|}{ CFRP } & \multicolumn{2}{c}{ GFRP } \\
\cline { 2 - 5 } & RT & CT & RT & CT \\
\cline { 2 - 5 } & 639.1 & 630.0 & 294.6 & 564.5 \\
\hline
\end{tabular}

\subsection{Failure strain of resin}

The stress strain curves of the monolithic epoxy resin are shown in Fig. 7. At room temperature, the failure strain was significantly higher than that at cryogenic temperature. It is generally known that the failure strain decreases at cryogenic temperature in comparison with that at room temperature due to the brittle behavior of polymer resin [8].

The observed failure strain of pure epoxy resin used in this study was about $0.21 \%$ at cryogenic temperature. According to the coefficient of thermal expansion $\alpha_{\mathrm{m}}$, the thermal strain of monolithic epoxy resin was calculated about $0.41 \%$ at cryogenic temperature. It was half in failure strain at cryogenic temperature, compared with that at room temperature.

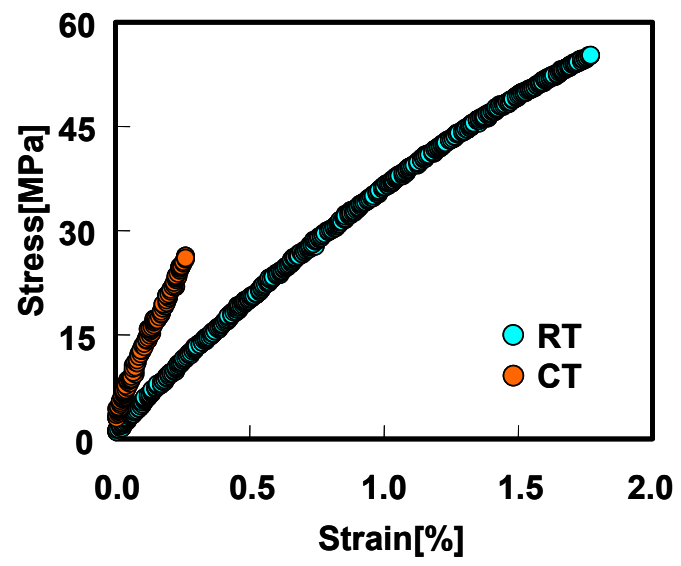

Figure 7: $\quad$ S-S curves of pure epoxy resin at RT and CT.

\subsection{Effect of thermal expansion coefficient on residual strength}

Carbon monofilament has small minus number of the coefficient of thermal expansion because carbon monofilament behaves like ceramic [9]. In this study, the coefficients of thermal expansions of CFRP and its pure resin were measured by TMA to estimate the residual stress at $-60^{\circ} \mathrm{C}$ up to room temperature (Table 4). The coefficient of thermal expansion of the epoxy resin was lower than that of the CFRP.

The thermal fatigue stress was applied to the CFRP and GFRP specimens [10-12]. The temperature change of the specimens was repeated from cryogenic 
temperature to room temperature. Figure 8 and 9 show the S-S curves of CFRP and GFRP, respectively after thermal fatigue test, in which the thermal stress was applied to the specimens before the static test.

Residual strengths [13] of CFRP and GFRP were almost equal to their each static strength even after 100 cycles of thermal fatigue loading. However the residual elastic modulus of CFRP was decreased by the cyclic thermal stress. There was the large difference in the coefficient of thermal expansion of carbon fiber and that of pure epoxy resin. Therefore the epoxy resin in CFRP should be damaged during the thermal fatigue test [14], because the magnitude of thermal free strain was larger than the failure strain of pure epoxy resin at cryogenic temperature as shown in section 3.3.

Table 4: The coefficient of thermal expansion of CFRP and the pure epoxy resin.

\begin{tabular}{c|c|c|c}
\hline Materials & $\mathrm{T}_{\max }\left({ }^{\circ} \mathrm{C}\right)$ & $\mathrm{T}_{\min }\left({ }^{\circ} \mathrm{C}\right)$ & The coefficient of thermal expansion $\left(-{ }^{\circ} \mathrm{C}\right)$ \\
\hline \multirow{2nnn}{*}{ CFRP } & \multirow{2}{*}{23} & \multirow{2}{*}{-60} & $6.8 \mathrm{e}-5$ \\
\cline { 1 - 1 } & & & $4.9 \mathrm{e}-5$ \\
\hline
\end{tabular}

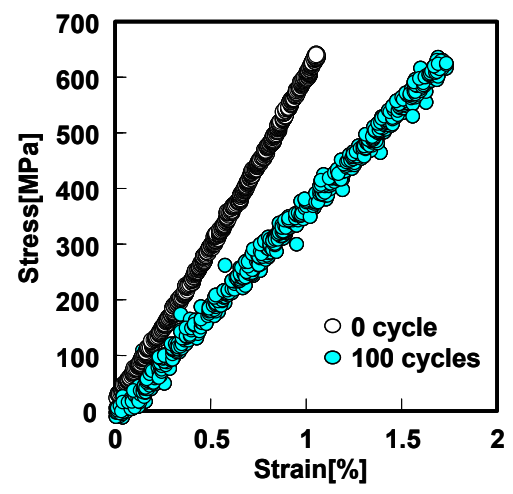

Figure 8: S-S curves of CFRP after thermal fatigue test at RT.

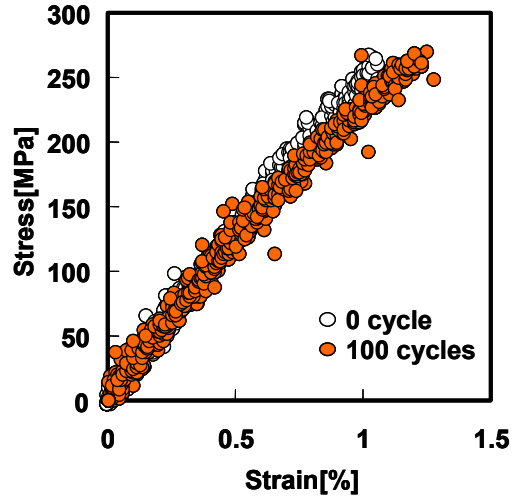

Figure 9: S-S curves of GFRP after thermal fatigue test at RT.

On the other hand, in Fig. 9, the residual elastic modulus of GFRP was equal to the static elastic modulus. This is explained by that the resin in GFRP was not damaged at cryogenic temperature, because the coefficient of thermal expansion of glass fiber was almost equal to that of pure vinyl ester resin.

\subsection{S-N curves of CFRP and GFRP}

The S-N curves of CFRP and GFRP at room and cryogenic temperature are shown in Fig. 10 and 11. CFRP had long durability at cryogenic temperature in high cycle fatigue compared with that at room temperature. The fatigue lives of GFRP at cryogenic temperature were also longer than those at room temperature. 
The knee-point appeared in the S-N curve of the GFRP at cryogenic temperature. The maximum stress at the knee point in S-N curve was almost coincident to the stress at knee point under static load at cryogenic temperature. It should be said that the stress at static knee-point is a threshold in cyclic fatigue loading which determines the damage progression mode in fatigue of GFRP.

The elastic modulus decay diagrams of CFRP was shown in Fig. 12, where $\gamma=90 \%$ at room and cryogenic temperature. The elastic modulus of CFRP at cryogenic temperature suddenly decreased in the final stage of fatigue, while such change was not observed at room temperature. Same result was observed in the paper [15]. At the cyclic number to failure in the condition of room temperature, the sharp decreasing in elastic modulus occurred at cryogenic temperature.

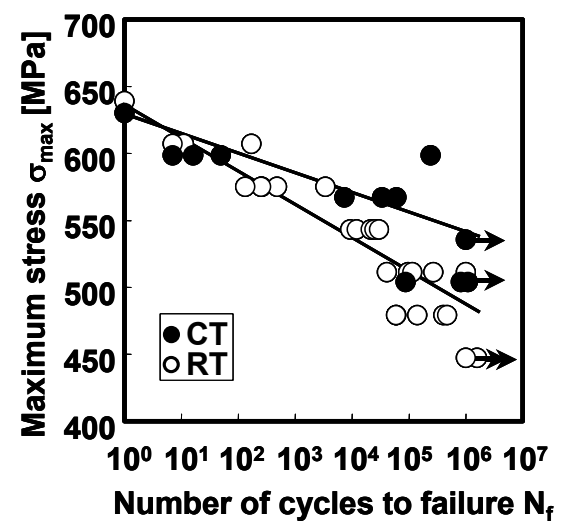

Figure 10: $\mathrm{S}-\mathrm{N}$ diagram of CFRP at RT and CT.

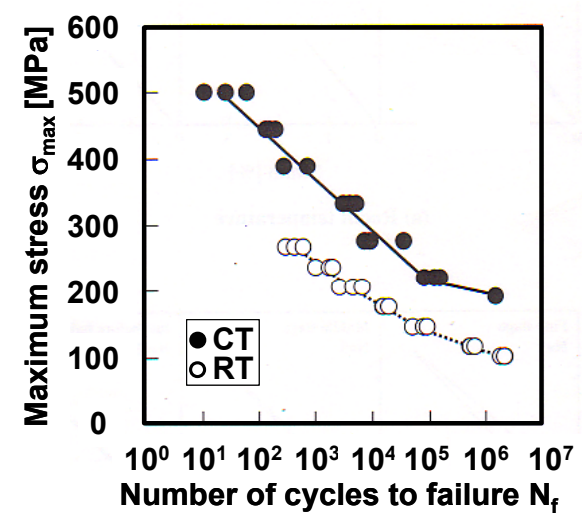

Figure 11: S-N diagram of GFRP at RT and CT.

Figure 13 shows the elastic modulus decay diagrams $(\gamma=90 \%)$ of GFRP at room and cryogenic temperature. At cryogenic temperature, the elastic modulus significantly decreased at first cycle of fatigue, while that was not decreased at room temperature. This should be explained by that, at cryogenic temperature, fatigue damage was accelerated in early stage of fatigue because the specimen was subjected to the load over the stress at knee point, even while the damage was not produced by local thermal stress of thermal fatigue test as shown in section 3.4 .

The fracture surface of CFRP after fatigue loading test $(\gamma=90 \%)$ at room and cryogenic temperature is shown in Fig. 14. At room temperature, fracture of the current CFRP was caused with the meta delamination appeared before the failure of fatigue at room temperature in CFRP. On the fracture surface, at cryogenic temperature, the epoxy resin was remained on the carbon fibers, while debonding was found around carbon fiber on the fracture surface of CFRP at room temperature. It should be said that, at cryogenic temperature, the carbon fiber was failed with accompanying critical crack propagation of the matrix due to the brittle of resin. 


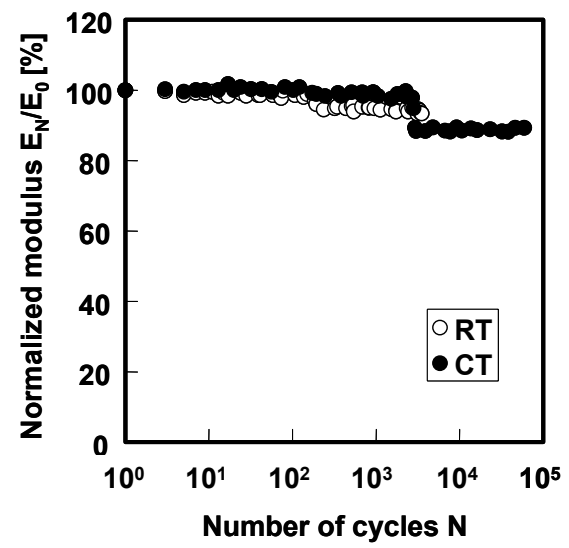

Figure 12: Elastic modulus decay of CFRP at RT and CT.

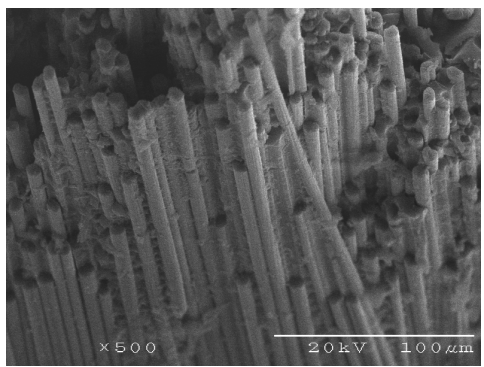

RT

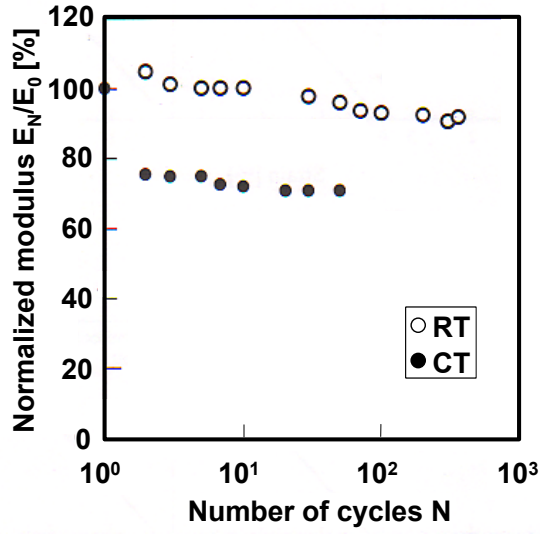

Figure 13: Elastic modulus decay of GFRP at RT and CT

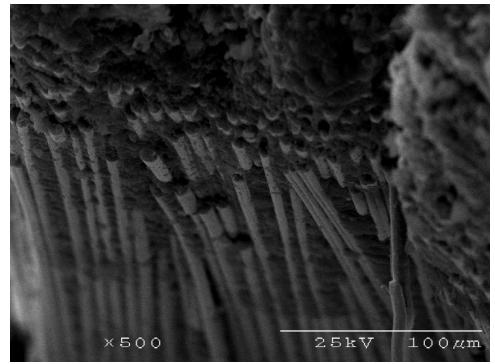

CT

Figure 14: Fracture surface of CFRP after fatigue test $(\gamma=90 \%)$.

\section{Conclusion}

(1) The fatigue lives of CFRP and GFRP at cryogenic temperature were higher than those at room temperature.

(2) At cryogenic temperature, the magnitude of thermal strain of pure epoxy resin was higher than the failure strain of the pure epoxy resin.

(3) At cryogenic temperature, the epoxy resin adhered carbon fiber remained on the fracture surface of CFRP applied cyclic loading $(\gamma=90 \%)$, while debonding was found around carbon fiber on the fracture surface of CFRP at room temperature.

(4) At cryogenic temperature, the elastic modulus of CFRP decreased in the final stage of fatigue, while that of GFRP decreases after the first cycle of fatigue.

(5) At cryogenic temperature, the stress at static knee-point of GFRP was the threshold in cyclic loading, which determined the damage progression mode in fatigue. 


\section{Acknowledgement}

This study was supported by the Ministry of Education, Culture, Sports, Science and Technology for RCAST (Doshisha University).

\section{References}

[1] H. Fukuda and G. Ben, Introduction to Mechanics of Composite, KOKIN Publishers, Tokyo, 1999

[2] T. Ishikawa, H. Kumazawa, Y. Morino, Y. Hayashi, ACCM-1, 1998, 437$1-4$

[3] F. Tomioka, H. Wada, JSME-A, 1992, 58-550

[4] A. Sakurai, Reinforced Plastic, Vol. 1, 10-17

[5] B. Fiedler, M. Hojo, S. Ochiai, K. Schulte, M. Ochi, Finite-element modelling of initial matrix failure in CFRP under static transverse tensile load, Composites Science and Technology, 61, 2001, 95-105

[6] Satoshi Kobayashi, Kazuhiro Terada, Nobuo Takeda, Evaluation of longterm durability in high temperature resistant CFRP laminates under thermal fatigue loading, Composites: Part B, 34, 2003, 753-759

[7] K. Yamada, K. Okubo, T. Fujii, 9th FRC2002, 2002, 201-206

[8] C. Henaff-Gardin, M.C. Lafarie-Frenot, Specificity of matrix cracking development in CFRP laminates under mechanical or thermal loadings, International Journal of Fatigue, 24, 2002, 171-177

[9] D. Hull and T. W. Clyne, An Introduction to Composite Materials, Second Edition, 1996

[10] N. K. Naik, V. K. Ganesh, Thermo-mechanical behaviour of plain weave fabric composites: Experimental investigations, Journal of Materials Science, 32, 1997, 267-277

[11] K. F. Rogers, D. M. Kingston-Lee, L. N. Phillips, B. Yates, M. Chandra, S. F. H. Parker, The thermal expansion of carbon-fibre reinforced plastics, Journal of Materials Science, 16, 1981, 2803-2818

[12] J. M. Gaitonde, M. V. Lowson, Low-temperature Thermal Expansion of PEEK, HTA and Some of Their Composites Reinforced with Carbon Fibres, Composites Science and Technology, 40, 1991, 69-85

[13] M. de Freitas, R. de Carvalho, Residual strength of a damaged laminated CFRP under compressive fatigue stresses, Composites Science and Technology, 66, 2006, 373-378

[14] M.C. Lafarie-Frenot, N.Q. Ho, Influence of free edge intralaminar stresses on damage process in CFRP laminates under thermal cycling conditions, Composites Science and Technology, 2005

[15] Surya D. Pandita, Ignaas Verpoest, Tension-tension fatigue behaviour of knitted fabric composites, Composite Structures, 64, 2004, 199-209 